\title{
Selective Growth of Layered Perovskites for Stable and Efficient Photovoltaics
}

Kyung Taek Cho, ${ }^{1}$ Yonghui Lee, ${ }^{1}$ Osbel Almora, ${ }^{2}$ Giulia Grancini, ${ }^{1}$ Jaehoon Ryu, ${ }^{3}$ Manuel Tschumi, ${ }^{1}$ Jyongsik Jang, ${ }^{3}$ Sanghyun Paek, ${ }^{1}{ }^{*}$ Germà Garcia-Belmonte, ${ }^{2}$ Mohammad Khaja Nazeeruddin ${ }^{1 *}$

${ }^{1}$ Group for Molecular Engineering of Functional Materials, EPFL Valais Wallis, CH-1951 Sion, Switzerland.

${ }^{2}$ Institute of Advanced Materials (INAM), Universitat Jaume I, 12006 Castelló, Spain.

${ }^{3}$ School of Chemical and Biological Engineering, Seoul National University, 599 Gwanangno, Gwanakgu, Seoul 151-742, Korea.

*Correspondence to: mdkhaja.nazeeruddin@epfl.ch

\begin{abstract}
Although perovskite solar cells (PSCs) are promising alternatives toward clean energy because of their high-power conversion efficiency (PCE) and low processing cost, their poor photostability and thermal stability issues are still preventing for practical applications. Here we demonstrate an innovative approach of realizing high stable and efficient PSCs by utilizing twodimensional (2D) perovskite as an interlayer between three-dimensional (3D) bulk perovskite film and hole transporting layer. The $2 \mathrm{D}$ perovskite layer formed by molecularly engineering exist distinctly on the 3D perovskite film and leads to enhance stability and performance of PSCs. The devices with 2D perovskite interlayer yielded $20.7 \%$ of PCE and retained $90 \%$ of the initial efficiency after one sun illumination for 800 hours at $50^{\circ} \mathrm{C}$ without any protective techniques.
\end{abstract}

One Sentence Summary: By inserting 2D perovskite layer between 3D perovskite film and hole transporting layer, high stable and efficient perovskite solar cells are achieved.

\section{Main Text:}

Perovskite solar cells (PSCs) with over 22\% of power conversion efficiency (PCE) are attracting extensive interest in renewable energy to deliver low-cost electricity and to reduce carbon dioxide emission (1-3). Notwithstanding, their commercialization and practical applications are still restricted by insufficient long term stabilities in ambient atmosphere. Therefore, advances particularly, improving device stability without sacrificing the high efficiency are vital for the future of PSCs. One of the reasons of efficiency degradation in PSCs is attributed to unstable perovskite materials itself composed of small organic cations $\left(\mathrm{A}^{+}\right)$, metal cations $\left(\mathrm{B}^{2+}\right)$ and halide anions $\left(\mathrm{X}^{-}\right)$, which form a three-dimensional (3D) crystal structure of $\mathrm{ABX}_{3}$ (4-6). To improve photostability, various cations formamidinium $\left(\mathrm{FA}^{+}\right)$, cesium $\left(\mathrm{Cs}^{+}\right)$, rubidium $\left(\mathrm{Rb}^{+}\right)$, and anions, bromide $\left(\mathrm{Br}^{-}\right)$, and chloride $\left(\mathrm{Cl}^{-}\right)$have been explored for mixed 3D perovskites; [FA/MA] $\mathrm{Pb}[\mathrm{I} / \mathrm{Br}]_{3}$ (7), [FA/Cs] $\mathrm{Pb}[\mathrm{I} / \mathrm{Br}]_{3}(8,9)$, or $[\mathrm{Rb} / \mathrm{Cs} / \mathrm{FA} / \mathrm{MA}] \mathrm{Pb}[\mathrm{I} / \mathrm{Br}]_{3}(10)$. However, these $3 \mathrm{D}$ perovskites are still unsatisfied for moisture and thermal stability to commercialization.

To overcome the limited stability of 3D perovskites, two-dimensional (2D) perovskites have been suggested as another replacement but at the expense of efficiency $(11,12)$. The $2 \mathrm{D}$ 
perovskite is formed when the size of the cation $\left(\mathrm{A}^{+}\right)$is enough large to isolate anionic metal layers in 3D perovskite phase. Although the recent Ruddlesden-Popper layered perovskite using n-butylammonium carried the PCE up to $12.5 \%$ (13), it suffers from lower PCE than that of the former 3D structure of mixed perovskite (14-16). Here, we developed a strategy of capping a 3D perovskite film by a 2D perovskite layer to take advantageous of high efficiency and stability of $3 \mathrm{D}$ and 2D perovskite, respectively. This approach differs from previous studies mixing 3D perovskite precursors and bulky cations homogeneously in perovskite films $(11,17-19)$. We discovered that the introduced 2D perovskite layer by molecularly engineering is formed separately between the 3D perovskite film and the hole transporting layer (HTL). A maximum PCE of $20.7 \%$, to best of our knowledge the highest efficiency among of devices including 2D perovskite, was achieved and the efficiency remained $90 \%$ of the original value after 800 hours of maximum power point tracking under full illumination at $50^{\circ} \mathrm{C}$ temperature.

We employed phenylethylammonium iodide (PEAI) to obtain a 2D perovskite $\left(\mathrm{PEA}_{2} \mathrm{PbI}_{4}\right)$ layer. The PEAI bulky cation has a large molecular radius that cause anionic layers in $3 \mathrm{D}$ architecture to be isolated and transform to 2D perovskite (19-21). In particular, the PEA ${ }^{+}$ was demonstrated to improve the phase stability in $\mathrm{FAPbI}_{3}$ when a small amount of PEAI was added as quasi-3D FA $\mathrm{PEA}_{1-\mathrm{X}} \mathrm{PbI}_{3}$ perovskite (22) and the change of valence band in $(\mathrm{PEA})_{2} \mathrm{MA}_{\mathrm{n}-1} \mathrm{~Pb}_{\mathrm{n}} \mathrm{I}_{3 \mathrm{n}+1}$ was very negligible (23), which is expected to have a little influence on hole transfer. We attained the $3 \mathrm{D} / 2 \mathrm{D}$ layered perovskite film by dynamic spin coating the PEAI isopropanol (IPA) solution on an optimized pristine $\mathrm{Cs}_{0.1} \mathrm{FA}_{0.74} \mathrm{MA}_{0.13} \mathrm{PbI}_{2.48} \mathrm{Br}_{0.39}$ (CFMPIB) perovskite film, followed by a post annealing process at $100^{\circ} \mathrm{C}$. This method can reduce the impact of the IPA solution on permeating to the pristine perovskite films and provide the thin PEAI film uniformly. For the pristine CFMPIB perovskite film, we exploited a lead excess stoichiometric ratio of a precursor perovskite solution $\left(\mathrm{FAI}: \mathrm{PbI}_{2}=1: 1.05\right)$ due to its positive effect on reducing defects in perovskite films and it was also aimed to be used for reacting with PEAI. The final perovskite film after annealing process is called L-CFM/P (layered perovskite with CFMPIB and quasi-PEA $2 \mathrm{PbI}_{4}$ ).

Figure 1A shows $x$-ray diffraction (XRD) spectra of the CFMPIB and the L-CFM/P films coated on $\mathrm{TiO}_{2} / \mathrm{FTO}$ substrates. In the pristine CFMPIB perovskite film, the $\mathrm{PbI}_{2}$ peak $\left(12.7^{\circ}\right)$ is observed demonstrating the presence of excess lead in CFMPIB precursor solution, and a $\delta$ phase of FA-based perovskite was remained. However, when the PEAI IPA solution $(10 \mathrm{mg} / \mathrm{ml})$ was coated on this film and annealed, the $\mathrm{PbI}_{2}$ and $\delta$-phase peaks disappeared and the new peaks at $5.44^{\circ}, 10.8^{\circ}, 16.3^{\circ}, 21.7^{\circ}$ and $27.3^{\circ}$, were appeared. We prepared a $\mathrm{PEA}_{2} \mathrm{PbI}_{4}$ film with anticipating that PEAI reacted to form the $\mathrm{PEA}_{2} \mathrm{PbI}_{4}$ perovskite and measured the XRD data. Comparison of peak positions demonstrated newly formed perovskite seems to accord with $\mathrm{PEA}_{2} \mathrm{PbI}_{4}$ phase, as expected $(20,22)$. Despite of constructing $2 \mathrm{D}$ perovskite, the other peaks for mixed 3D perovskite scarcely modified. For the (111) crystal plane of the main 3D perovskite phase, the $2 \theta$ around $14^{\circ}$ was zoomed and the full-width at half-maximum (FWHM) of the CFMPIB and the L-CFM/P were estimated in Fig. S1. Whereas the $\mathrm{PEA}_{2} \mathrm{PbI}_{4}$ peak at $10.8^{\circ}$ increased and the $\mathrm{PbI}_{2}$ peak at $12.7^{\circ}$ disappeared when the films were heated, the main CFMPIB perovskite peak at $14.1^{\circ}$ was not shifted and reduced. This change represents a distinct $\mathrm{PEA}_{2} \mathrm{PbI}_{4}$ perovskite was generated in the CFMPIB perovskite film. In Fig. S2, a strong peak at $4.69^{\circ}$ revealing PEAI was reduced as the heating time increased. This means post annealing is needed for reacting and forming $2 \mathrm{D}$ perovskite. We aside fabricated additional perovskite film from a solution including the CFMPIB precursor and PEAI together, where the amount of added PEAI was matched the excess molar ratio of $\mathrm{PbI}_{2}$ in the CFMPIB precursor solution (FAI:PEAI:PbI $2=$ 
1:0.05:1.05). In Fig. $\mathrm{S} 3$, the $\mathrm{PbI}_{2}$ peak was not detected in the XRD data like the L-CFM/P film. Quite differently, however, the peak of $\mathrm{PEA}_{2} \mathrm{PbI}_{4}$ in region around $5^{\circ}$ was not created. It indicates that only our strategy of spin-coating PEAI solution on pristine CFMPIB perovskite films can produce the 2D perovskite effectively in the bulk perovskite layer.

After spin coating PEAI solution, the color of the L-CFM/P film characterizes to dark green compared to the pristine CFMPIB film, as presented photo-images of pristine CFMPIB and L-CFM/P perovskite films in the inset in Fig. 1B. We measured Ultraviolet-Visible (UV-vis) absorption and the reflectance spectra of CFMPIB, L-CFM/P, and $\mathrm{PEAI}_{2} \mathrm{PbI}_{4}$ perovskite films (Fig. 1B and 1C). The slight redshift of the band edge is visible when forming 2D perovskite. It is an agreement with the literature (22), where the addition of small amount PEAI to mixed 3D perovskite shows slight redshift of absorption while the large amount leads to the blue shifted absorption. The greenish color of L-CFM/P can be consistent with a small hump at $500 \mathrm{~nm}$ in reflectance spectra, showing an independent perovskite emitting a green light was created.

The photoluminescence (PL) of CFMPIB and L-CFM/P perovskites was carried out from top of perovskite and bottom of $\mathrm{TiO}_{2}$ (Fig. 2 and Fig. S4). We used an excitation light of $450 \mathrm{~nm}$ which has a penetration depth less than $100 \mathrm{~nm}(24,25)$. That implies these PL data are correlated with partially thin layers at top and bottom of perovskite layers. For CFMPIB, the PL peaks occurred at $759 \mathrm{~nm}$ and $775 \mathrm{~nm}$ in top surface and bottom interface of the perovskite film, respectively. Although this small difference is observed, which might be resulted from the effect of the mesoporous- $\mathrm{TiO}_{2}$ structure, these PL peaks are attributable to same pristine CFMPIB perovskite. However, the L-CFM/P film shows totally different peak positions and intensities between top and bottom of perovskite film. From the top surface of the L-CFM/P film a strong peak at $508 \mathrm{~nm}$ and a week peak at $765 \mathrm{~nm}$ were displayed, while a $\mathrm{TiO}_{2}$ side of perovskite film had a peak at $770 \mathrm{~nm}$. The peak at $508 \mathrm{~nm}$ from top side would be derived from newly formed 2D perovskite having large bandgap and it is consistent with XRD data. Thus, it is determined that the new 2D perovskite was constructed only at top layer of the perovskite film. In addition, it can be assumed the thickness of this $\mathrm{PEA}_{2} \mathrm{PbI}_{4}$ perovskite layer is very thin because the small peak of $765 \mathrm{~nm}$ indicating CFMPIB perovskite was also detected in PL spectra of top side. Definitely, the pristine perovskite phase was barely affected by PEAI treatment, except the modification of top layer to 2D perovskite film.

We fabricated the mesoscopic perovskite solar cells with the pristine CFMPIB perovskite and the L-CFM/P perovskite. Both of devices have the same architecture (fluorine doped tin oxide/ blocking and mesoporous $\mathrm{TiO}_{2}$ / perovskite/ spiro-OMeTAD/ gold) except using different perovskite films. The top view scanning electron microscopy (SEM) images of perovskite films revealed stark differences between before and after PEAI coating (Fig. 3A and 3B). The pristine CFMPIB perovskite film deposited on top of mesoporous $\mathrm{TiO}_{2}$ layer showed compact, pinhole free, and large grains having distinct grain boundaries like a rock wall. However, the forming 2D perovskite on top of the perovskite layer changed to more homogeneous and smoother films, and grain boundaries were reduced. The mitigated grain boundaries indicate decreased defects in perovskite layer, leading relieved charge recombination. Atomic force microscope (AFM) measurement was examined to further scrutinize the surface of the perovskite film (Fig. S5). The root mean square roughness $\left(\mathrm{R}_{\mathrm{q}}\right)$ value decreased after spin-coating PEAI and annealing, from $25.01 \mathrm{~nm}$ to $18.76 \mathrm{~nm}$. In contrast to the variation on top surfaces of perovskite films, a crosssectional SEM images of them displayed no distinct difference (Fig. 3C and Fig. S6). This change of morphology processed, especially, at the top surface of the perovskite film and thin 2D 
perovskite layer was newly formed. After building the thin 2D perovskite layer on CFMPIB films, the creation of band offset inside perovskite films is expected to cause an increase of charge transfer of photo-generated electrons to $\mathrm{TiO}_{2}$ and blocking the charge recombination at the interface of perovskite/HTL under illumination (26). Based on photoluminescence and Tauc plot (Fig. S7), the energy level diagram of L-CFM/P was illustrated in Fig. S8. Considering the valence level coherence between the CFMPIB and $\mathrm{PEA}_{2} \mathrm{PbI}_{4}$ perovskite (23), the holes in the CFMPIB layer were expected to move to HTL without any impediment. However, the photoexcited electrons in a conduction band of CFMPIB would be prevented from diffusing to HTL because of higher conduction energy level of $\mathrm{PEA}_{2} \mathrm{PbI}_{4}$.

The effect of this strategy was proved in photovoltaic performance of complete devices. Fig. 3D presents the current density-voltage $(\mathrm{J}-\mathrm{V})$ curves and hysteresis of devices with pristine CFMPIB and L-CFM/P perovskite films. Both of cells showed negligible hysteresis. We fabricated more than 100 PSCs with L-CFM/P and the PCEs are summarized in histogram (Fig. $3 \mathrm{E})$. The devices with $3 \mathrm{D} / 2 \mathrm{D}$ perovskite films presented improved efficiencies with a high degree of reproducibility. The best performing device with L-CFM/P achieved $1.15 \mathrm{~V}\left(\mathrm{~V}_{\mathrm{OC}}\right)$, $22.73 \mathrm{mAcm}^{-2}\left(\mathrm{~J}_{\mathrm{SC}}\right)$, and $0.794(\mathrm{FF})$, yielding a PCE to $20.75 \%$. We recorded the corresponding incident photon conversion efficiency (IPCE) of each PSCs (Fig. 3F). Although both of devices show high IPCE close to $90 \%$, the device employing the passivating $2 \mathrm{D}$ perovskite layer has a little higher efficiency than that of the pristine perovskite device in the whole wavelength range from $400 \mathrm{~nm}$ to $800 \mathrm{~nm}$. The integrated $\mathrm{J}_{\mathrm{SC}}$ values from EQE curve with AM1.5G solar spectrum are agreement with the tendency obtained from J-V measurement. We also prepared another device using a precursor solution including with CFMPIB and PEAI, examined for XRD spectra comparison (Fig. S9). Incorporating PEAI within the perovskite film homogeneously exhibited the dramatically dropped performance rather.

To investigate the charge transfer kinetics within perovskite films, the time resolved PL decay was performed by the emission at $770 \mathrm{~nm}$ with the incident exciting light at $480 \mathrm{~nm}$ to the perovskite surface. In Fig. S11, the L-CFM/P showed faster decay in PL lifetime than the pristine CFMPIB film. It confirms the charge extraction in L-CFM/P films, where holes transfer from inside CFMPIB perovskite to top $\mathrm{PEA}_{2} \mathrm{PbI}_{4}$ perovskite while electrons transfer to the opposite direction. The enhanced charge transfer implied the charge recombination would be restrained, thus an enlargement in the charge recombination resistance should be expected. Electrochemical impedance spectroscopy (EIS) on both of samples supported the data from PL decay about charge transport at the surficial interfaces and the reduced charge recombination (Fig. 4A). In Nyquist plot under the same open circuit voltage $(880 \mathrm{mV})$, the L-CFM/P device showed the bigger second arc at intermediate and low frequencies than the CFMPIB cells, where the second arc is presumably associated with the interface charge recombination. The effective recombination time constant, obtained from the fitting of the arc to the equivalent circuit model of inset of Fig. 4A, increased twice from $173 \mathrm{~ms}$ for the CFMPIB to $385 \mathrm{~ms}$ for the L-CFM/P based devices.

As the main purpose of capping 2D perovskite layer, we examined the long term stability test of the 2D perovskite containing films under dark storage and continuous illumination. For dark storage, the L-CFM/P enhanced device stabilities compared to the pristine CFMPIB perovskite (Fig. 4B). Under dark dry condition, the device made with L-CFM/P maintained the initial PCE of $20 \%$, while one with pristine CFMPIB was decreased gradually. Fig. 4C presents maximum power point tracking (MPPT) of the un-encapsulated CFMPIB and L-CFM/P PSCs 
for 800 hours at $50^{\circ} \mathrm{C}$ under continuous illumination of full intensity in argon atmosphere. The L-CFM/P devices displayed impressive improved stability even at $50^{\circ} \mathrm{C}$ temperature and without UV-filter and encapsulation. The small initial drop and continuous degeneration of devices could be addressed by the harmful photocatalytic effect of $\mathrm{TiO}_{2} \mathrm{ETL}$ at $50^{\circ} \mathrm{C}$. $\mathrm{TiO}_{2}$ based PSCs have shown the serious UV-induced degradation at interface perovskite and $\mathrm{TiO}_{2}$, which lead to reduce the performance $(14,15)$. We found the L-CFM/P can be feasible on various ETLs or configuration by testing on the passivated planar $\mathrm{SnO}_{2}$ ETL (27) (Fig. S11). It was obtained the excellent photo-stability retaining $90 \%$ of the first PCE after 800 hours under same condition to the test of $\mathrm{TiO}_{2}$ based devices (Fig. S12).

Despite spiro-OMeTAD used in these PSCs as the HTM, which is known to cause degradation of perovskite films from metal electrode diffusion and morphological decomposition $(10,28)$, the L-CFM/P cells showed surprising stable performance even at $50^{\circ} \mathrm{C}$. Thus, it should be noted that 2D perovskite capping layer between perovskite and HTM can minimized the negative effects of the organic HTM as a buffer layer. Our strategy of interface engineering for inserting 2D perovskite layer achieves to upgrade the perovskite film itself on stability as well as efficiency, which will be a stepping stone of applying PSCs to commercial products. 
Subheads. These can be included in Research Articles or Reviews and should be brief.

\section{References and Notes:}

1. B. Obama, The irreversible momentum of clean energy. Science 355, 126-129 (2017).

2. N.-G. Park, M. Grätzel, T. Miyasaka, K. Zhu, K. Emery, Towards stable and commercially available perovskite solar cells. Nature Energy 1, 16152 (2016).

3. N. R. E. L. (NREL), Research Cell Efficiency Records (http://www.nrel.gov/ncpv/images/efficiency_chart.jpg). Research Cell Efficiency Records.

4. B. Conings et al., Intrinsic Thermal Instability of Methylammonium Lead Trihalide Perovskite. Advanced Energy Materials 5, 1500477 (2015).

5. W. Nie et al., Light-activated photocurrent degradation and self-healing in perovskite solar cells. 7, 11574 (2016).

6. Y. Han et al., Degradation observations of encapsulated planar $\mathrm{CH} 3 \mathrm{NH} 3 \mathrm{PbI} 3$ perovskite solar cells at high temperatures and humidity. Journal of Materials Chemistry A 3, 81398147 (2015).

7. X. Li et al., A vacuum flash-assisted solution process for high-efficiency large-area perovskite solar cells. Science 353, 58-62 (2016).

8. Z. Wang et al., Efficient and Air-Stable Mixed-Cation Lead Mixed-Halide Perovskite Solar Cells with n-Doped Organic Electron Extraction Layers. Advanced Materials 29, 164186 (2016).

9. J.-W. Lee et al., Formamidinium and Cesium Hybridization for Photo- and MoistureStable Perovskite Solar Cell. Advanced Energy Materials 5, n/a-n/a (2015).

10. M. Saliba et al., Incorporation of rubidium cations into perovskite solar cells improves photovoltaic performance. Science 354, 206-209 (2016).

11. I. C. Smith, E. T. Hoke, D. Solis-Ibarra, M. D. McGehee, H. I. Karunadasa, A Layered Hybrid Perovskite Solar-Cell Absorber with Enhanced Moisture Stability. Angewandte Chemie International Edition 53, 11232-11235 (2014).

12. D. H. Cao, C. C. Stoumpos, O. K. Farha, J. T. Hupp, M. G. Kanatzidis, 2D Homologous Perovskites as Light-Absorbing Materials for Solar Cell Applications. Journal of the American Chemical Society 137, 7843-7850 (2015).

13. H. Tsai et al., High-efficiency two-dimensional Ruddlesden-Popper perovskite solar cells. Nature 536, 312-316 (2016).

14. S. S. Shin et al., Colloidally prepared La-doped BaSnO3 electrodes for efficient, photostable perovskite solar cells. Science 356, 167-171 (2017).

15. H. Tan et al., Efficient and stable solution-processed planar perovskite solar cells via contact passivation. Science 355, 722-726 (2017).

16. N. J. Jeon et al., Compositional engineering of perovskite materials for high-performance solar cells. Nature 517, 476-480 (2015).

17. G. Grancini et al., One-Year stable perovskite solar cells by 2D/3D interface engineering. 8, 15684 (2017).

18. D. Bi et al., High-Performance Perovskite Solar Cells with Enhanced Environmental Stability Based on Amphiphile-Modified CH3NH3PbI3. Advanced Materials 28, 29102915 (2016).

19. X. Gan et al., 2D homologous organic-inorganic hybrids as light-absorbers for planer and nanorod-based perovskite solar cells. Solar Energy Materials and Solar Cells 162, 93102 (2017). 
20. L. N. Quan et al., Ligand-Stabilized Reduced-Dimensionality Perovskites. Journal of the American Chemical Society 138, 2649-2655 (2016).

21. B.-E. Cohen, M. Wierzbowska, L. Etgar, High Efficiency and High Open Circuit Voltage in Quasi 2D Perovskite Based Solar Cells. Advanced Functional Materials 27, 1604733 (2017).

22. N. Li et al., Mixed Cation FAxPEA1-xPbI3 with Enhanced Phase and Ambient Stability toward High-Performance Perovskite Solar Cells. Advanced Energy Materials 7, 1601307 (2016).

23. M. Yuan et al., Perovskite energy funnels for efficient light-emitting diodes. Nat Nanotechnol 11, 872-877 (2016).

24. C. Roldan-Carmona et al., High efficiency methylammonium lead triiodide perovskite solar cells: the relevance of non-stoichiometric precursors. Energy \& Environmental Science 8, 3550-3556 (2015).

25. J. J. van Franeker et al., Monitoring Thermal Annealing of Perovskite Solar Cells with In Situ Photoluminescence. Advanced Energy Materials 7, 1601822 (2017).

26. K. T. Cho et al., Highly efficient perovskite solar cells with a compositionally engineered perovskite/hole transporting material interface. Energy \& Environmental Science 10, 621627 (2017).

27. Y. Lee et al., Enhanced charge collection with passivation of the tin oxide layer in planar perovskite solar cells. J. Mater. Chem. A, (2017).

28. K. Domanski et al., Not All That Glitters Is Gold: Metal-Migration-Induced Degradation in Perovskite Solar Cells. ACS Nano 10, 6306-6314 (2016).

29. S. Paek et al., From Nano- to Micrometer Scale: The Role of Antisolvent Treatment on High Performance Perovskite Solar Cells. Chemistry of Materials 29, 3490-3498 (2017).

Acknowledgments: All of data are reported in the main text and supplementary material. K.C. and S.P. designed the idea, and fabricated the devices. K.C. conducted XRD, UV-vis, and SEM. Y.H. fabricated $\mathrm{SnO}_{2}$ based devices. O.A. and G.G.B. conducted impedance measurement. G.G. conducted PL measurement. J.R. and J.J conducted AFM measurement. T. M. set up stability testing. M.N. supervised the overall project. The authors acknowledge SNSF NRP 70 project; number:407040_154056, European Commission H2020-ICT-2014-1,SOLEDLIGHT project, grant agreement N1: 643791 and the SwissState Secretariat for Education, Research and Innovation (SERI), and CTI 15864.2 PFNM-NM, Solaronix, Aubonne, Switzerland. G. G. acknowledges support from the 'EPFL Fellows' fellowship program co-funded by Marie Skłodowska-Curie, Horizon 2020 grant agreement no. 665667 and Y. L. acknowledges support from Special funding for energy research, managed by Prof. Andreas ZU“TTEL, Funds N1 563074. 

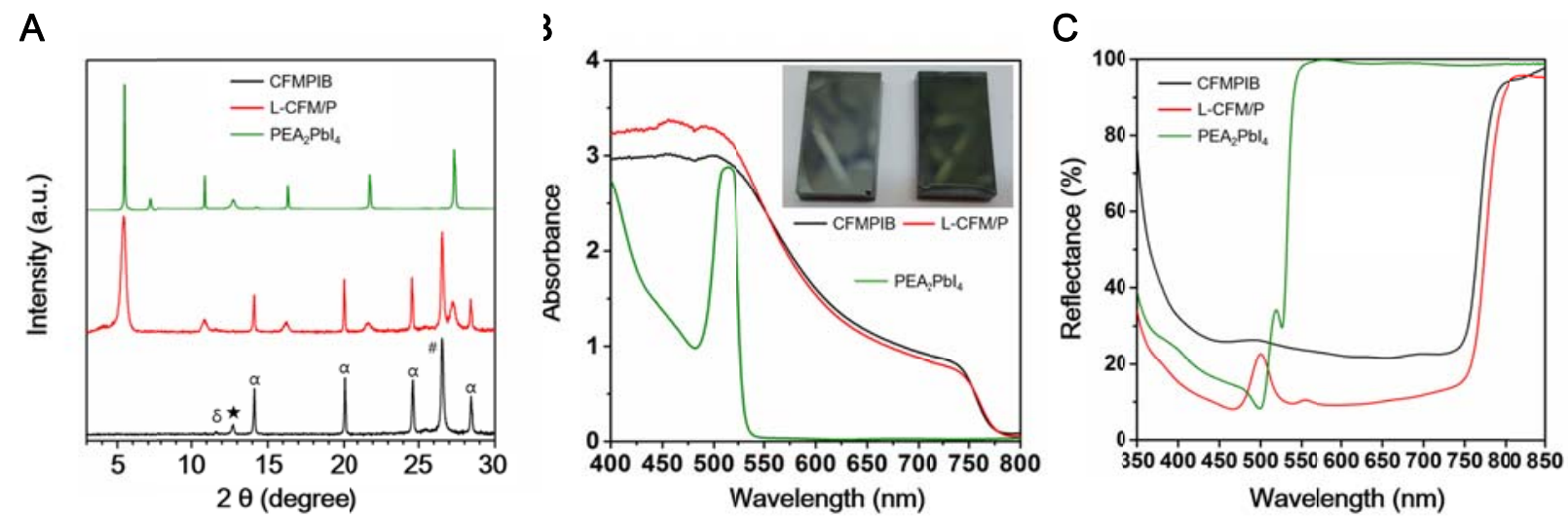

Fig. 1. Characterization of CFMPIB (Cs $\left.{ }_{0.1} \mathrm{FA}_{0.74} \mathrm{MA}_{0.13} \mathrm{PbI}_{2.48} \mathrm{Br}_{0.39}\right), \mathrm{L}-\mathrm{CFM} / \mathrm{P}\left(\mathrm{PEA}_{2} \mathrm{PbI}_{4}\right.$ layered on CFMPIB), and $\mathrm{PEA}_{2} \mathrm{PbI}_{4}$ perovskite. (A) XRD data, (B) UV-vis spectroscopy, (C) diffuse reflectance spectra of these three perovskite films. In XRD spectra, $\alpha, \delta$, $\star$ and $\#$ denote diffraction peaks corresponding to the $\alpha, \delta$ phase of $\mathrm{FAPbI}_{3}$ based perovskite, $\mathrm{PbI}_{2}$ and $\mathrm{FTO}$, respectively. The inset images in (B) show photo images of CFMPIB and L-CFM/P films. All of perovskite films examined for these measurements were prepared as coated on mesoporous $\mathrm{TiO}_{2} /$ compact $\mathrm{TiO}_{2} /$ FTO substrates.
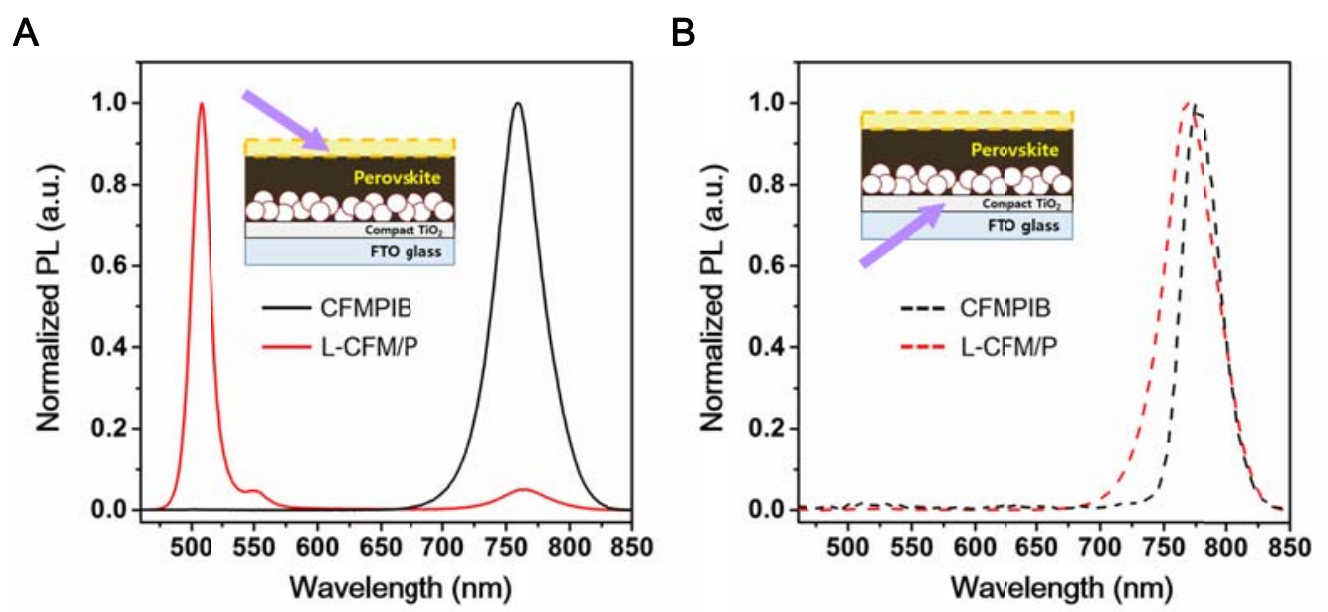

Fig. 2. Comparison of photoluminescence emission spectra of CFMPIB and L-CFM/P perovskites. (A and B) Steady-state normalized PL spectra excited with a laser of $450 \mathrm{~nm}$ from top surface of perovskite films (A) and bottom of perovskite films (B). Non-normalized PL of CFMPIB, L-CFM/P, and $\mathrm{PEA}_{2} \mathrm{PbI}_{4}$ is shown in Figure S4. 
A

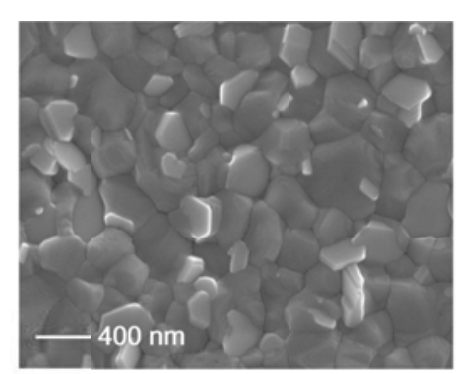

D

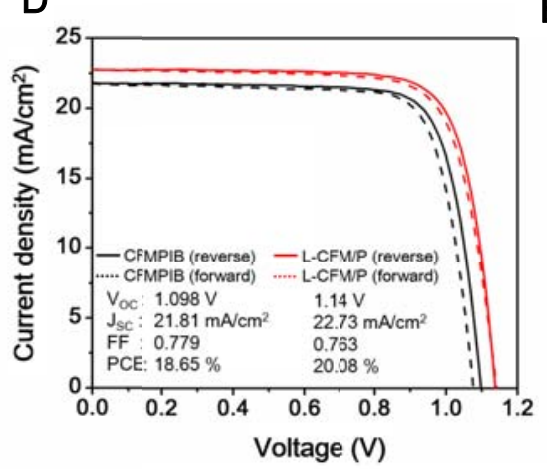

3

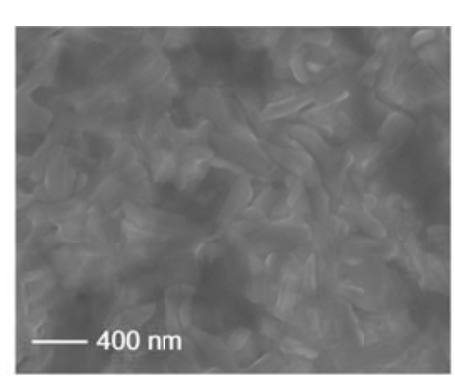

E

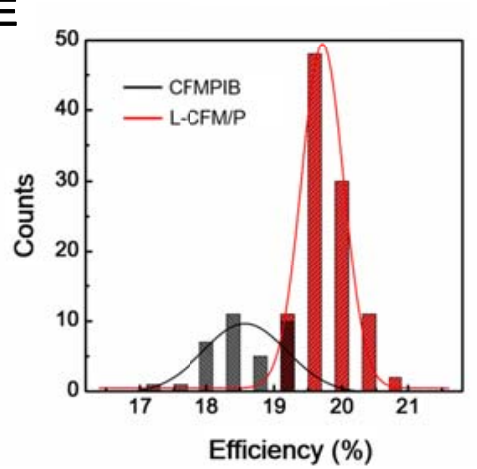

C

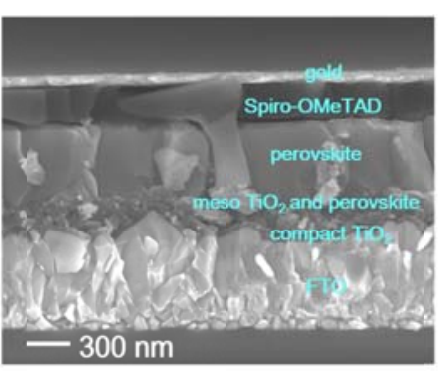

$\mathrm{F}$

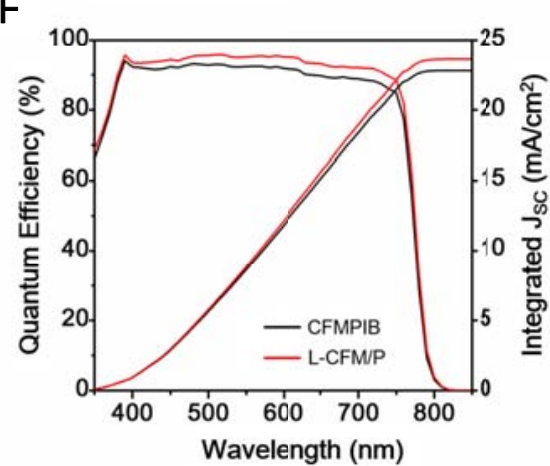

Fig. 3. Morphologies of perovskite films and photovoltaic performances of PSCs with CFMPIB and L-CFM/P. (A and B) Top-view images from scanning electron microscopy (SEM) of CFMPIB film (A) and L-CFM/P film (B). (C) Cross-sectional SEM image of complete device fabricated with L-CFM/P (CFMPIB was also followed same configuration as seen in Fig. S6). (D) J-V curves and hysteresis of PSCs with scan rate of $25 \mathrm{mV} / \mathrm{s}$. (E) Histograms of the PCEs. (G) EQE spectrums and integrated $\mathrm{J}_{\mathrm{SC}}$ from EQE. 
A

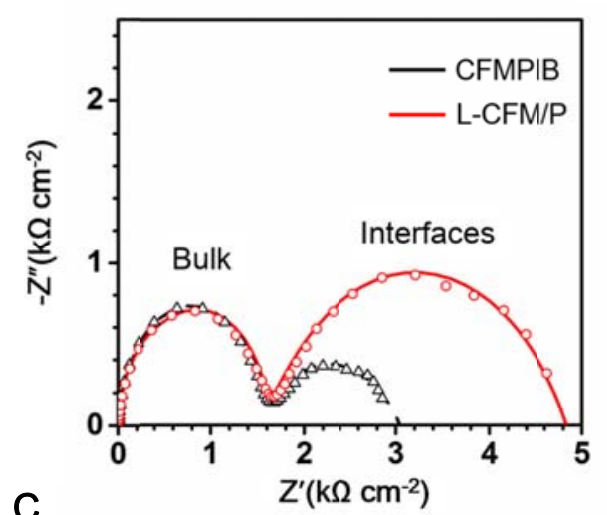

B

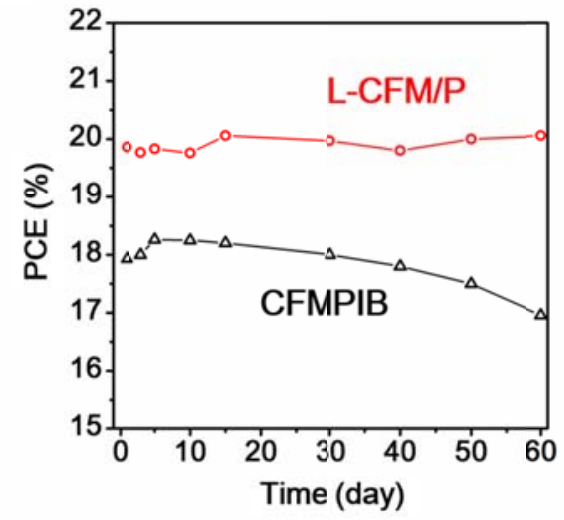

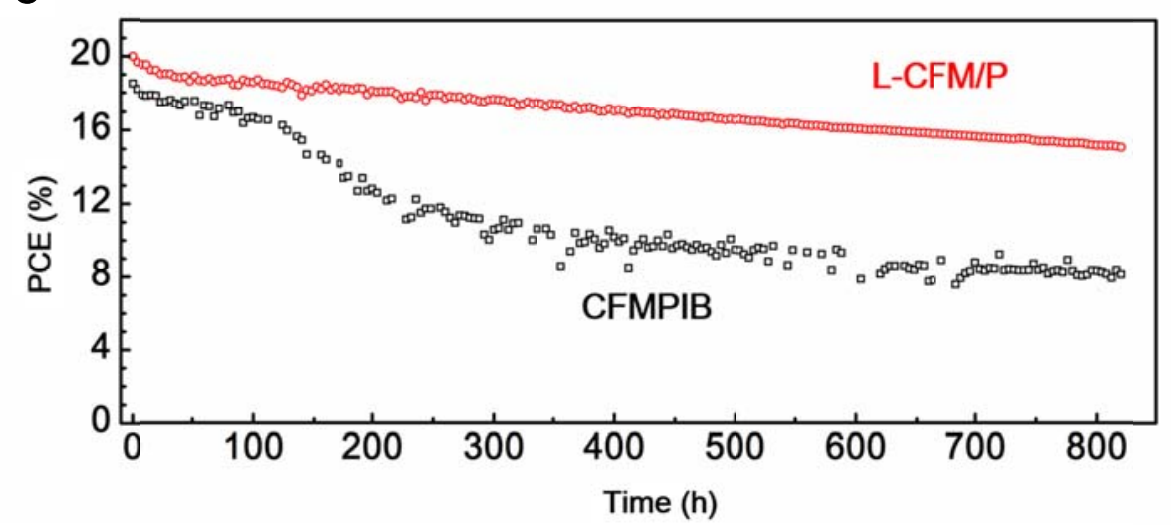

Fig. 4. and long term stability of PSCs with CFMPIB and L-CFM/P. (A) Open circuit EIS spectra with clear differences toward the low frequency range. The solid lines are the fittings to the equivalent circuit of the insert. (B) Dark storage stability of devices with CFMPIB and L$\mathrm{CFM} / \mathrm{P}$. All of cells are not encapsulated and kept in dark dry cabinet where the relative humidity is about $5 \%$ and measured in ambient atmosphere. (C) Photo-stability test from maximum power point tracking under continuous illumination of full intensity without any UV filter and encapsulation.

\section{Supplementary Materials:}

Materials and Methods

Figures S1-S12

References $(23,27,29)$ 


\section{Supplementary Materials:}

This section includes the actual text of the Supplementary Materials, which can include any or all of the preceding items, and figure captions and tables that can easily be incorporated into one supplementary material file. Please edit the list above as appropriate and include it at the end of your main paper. If there are additional files that cannot be easily accommodates (e.g., movies or large tables), please include captions here.

\section{Materials and Methods:}

\section{$\underline{\text { Materials }}$}

Formamidinium iodide (FAI) and methylamonium bromide (MABr) were purchased from Dyesol. Lead iodide $\left(\mathrm{PbI}_{2}\right)$ and lead bromide $\left(\mathrm{PbBr}_{2}\right)$ were from TCI. Cesium iodide (CsI) was from $\mathrm{GmbH}$. Phenylethylammonium iodide (PEAI) was synthesized (20). Phenylethylamine of $10 \mathrm{ml}$ was diluted in $20 \mathrm{ml}$ of anhydrous ethanol and cooled down by an ice bath. With vigorous stirring, $\mathrm{HI}\left(55 \mathrm{wt} \%\right.$ in $\mathrm{H}_{2} \mathrm{O}$, Sigma Aldrich) of $20 \mathrm{ml}$ was dropped slowly. After stirring for $20 \mathrm{~min}$, the colorless precipitate was filtered. The precipitate was washed with diethyl ether and dissolved in methanol twice. To obtain pure white crystals, the PEAI precipitate was recrystallized twice and stored under vacuum oven overnight to dry.

\section{$\underline{\text { Perovskite solar cell fabrication }}$}

FTO glass substrates (Nippon sheet glass) were sequentially cleaned with the detergent solution, acetone, and ethanol. And then by spray pyrolysis deposition, a compact $\mathrm{TiO}_{2}$ layer was coated on the cleaned FTO substrate heated at $450^{\circ} \mathrm{C}$. A precursor solution is diluting titanium diisopropoxide (Sigma-Aldrich) in ethanol $(0.6 \mathrm{ml}: 10 \mathrm{ml})$. After cooling, mesoporous $\mathrm{TiO}_{2}$ film was prepared coating a diluted $\mathrm{TiO}_{2}$ paste (Dyesol 30 NR-D) solution in ethanol. Right after spin-coating at $2000 \mathrm{rpm}$ for $20 \mathrm{~s}$, the substrates were sintered on a hot plate at $500^{\circ} \mathrm{C}$ for 30 min. For doping $\mathrm{Li}$ on $\mathrm{TiO}_{2}$, films were treated with $0.1 \mathrm{M}$ Lithium bistrifluoromethanesulfonimidate solution (Li-TFSI, Aldrich) in acetonitrile by spin-coating at $3000 \mathrm{rpm}$ for $10 \mathrm{~s}$, and finally baked at $500^{\circ} \mathrm{C}$ for $30 \mathrm{~min}$ again. The lead excess $\left(\mathrm{FAPbI}_{3}\right)_{0.85}\left(\mathrm{MAPbBr}_{3}\right)_{0.15}$ precursor solution was prepared by mixing $\mathrm{FAI}(1.1 \mathrm{M}), \mathrm{PbI}_{2}(1.15$ $\mathrm{M}), \operatorname{MABr}(0.2 \mathrm{M})$ and $\mathrm{PbBr}_{2}(0.2 \mathrm{M})$ in a mixed solvent of DMF: $\mathrm{DMSO}=4: 1$ (volume ratio). Another solution of $\mathrm{CsPbI}_{3}$ was also prepared as $1.15 \mathrm{M}$ in DMF: DMSO (same volume ratio). For triple cations mixed perovskite solution, $\left(\mathrm{FAPbI}_{3}\right)_{0.85}\left(\mathrm{MAPbBr}_{3}\right)_{0.15}$ and $\mathrm{CsPbI}_{3}$ solutions were mixed as $10 \mathrm{vol} \%$ ratio. The solution was then spin-coated at $1000 \mathrm{rpm}$ for $10 \mathrm{~s}$ and continuously at $4000 \mathrm{rpm}$ for $30 \mathrm{~s}$ in nitrogen glove box. After entering the second step, $100 \mu \mathrm{L}$ of anhydrous trifluorotoluene was poured at 15 seconds before the finish (29). Films were then annealed at $100^{\circ} \mathrm{C}$ for $60 \mathrm{~min}$. For forming additional 2D perovskite film on top of this perovskite film, cooled substrates were treated with a PEAI isopropanol solution. $100 \mu \mathrm{L}$ of PEAI solution $(15 \mathrm{mg} / \mathrm{ml})$ were spin-coated on the as-prepared perovskite films at $4000 \mathrm{rpm}$ like dropping anti-solvent on perovskite solution, and annealed at $100^{\circ} \mathrm{C}$ for $5 \mathrm{~min}$. Finally, SpiroOMeTAD was spin-coated at $4000 \mathrm{rpm}$ for $20 \mathrm{~s}$. The $70 \mathrm{mM}$ Spiro-OMeTAD solution was prepared by dissolving in chlorobenzene with 4-tert-butylpyridine, Li-TFSI in acetonitrile, and $\mathrm{Co}[\mathrm{t}-\mathrm{BuPyPz}]_{3}[\mathrm{TFSI}]_{3}$ (FK209) in acetonitrile at the molar ratio of Spiro : FK209 : Li-TFSI : TBP of $1: 0.03: 0.5: 3.3$. Devices were completed with a thermal evaporation of $70 \mathrm{~nm}$ thickness gold counter electrode. 
For devices based planar $\mathrm{SnO}_{2}$ ETL (27), compact $\mathrm{TiO}_{2} / \mathrm{FTO}$ substrates were prepared as explained previously for mesoporous $\mathrm{TiO}_{2}$. A PTO layer was prepared by spin-coating a precursor solution of $\mathrm{SnCl}_{4}$ (Acros) dissolved in water. $0.1 \mathrm{M} \mathrm{SnCl}_{4}$ aqueous solution was spincoated at 5,000 rpm for $10 \mathrm{~s}$ on the substrates to get $\sim 20 \mathrm{~nm}$ thickness. Then the substrates were transferred onto a hotplate and heated at $180^{\circ} \mathrm{C}$ for $1 \mathrm{~h}$ and cooled down.

\section{$\underline{\text { Perovskite characterization }}$}

X-ray diffraction (XRD) analysis in an angle range of $2 \theta=3^{\circ}$ to $30^{\circ}$ was carried out using a Bruker D8 Advance diffractometer. The absorbance and reflectance measurements were performed with an integrating sphere using UV/Vis/NIR spectroscopy (PerkinElmer ambda). Photoluminescence were measured using Flourolog-3 (Horiba Scientific) with excitation laser of $450 \mathrm{~nm}$. A high-resolution scanning electron microscope (SEM) images were obtained with ZEISS Merlin with $5 \mathrm{kV}$. Time-resolved PL experiments were performed with a spectrophotometer (Gilden Photonics) using a pulsed source at $480 \mathrm{~nm}$ (Ps diode lasers BDS$\mathrm{SM})$. The time-resolved signal were recorded by a Time Correlated Single Photon Counting detection technique with a time resolution of $1 \mathrm{~ns}$.

The EIS measurements were carried out with an SP-200 BioLogic potentiostat being the AC perturbation of $10 \mathrm{mV}$ from $75 \mathrm{mHz}$ to $1 \mathrm{MHz}$, at room temperature with $5 \%$ of humidity. The illumination was tuned with an Oriel DC Regulated Illuminator in order to make $V_{\text {oc }}=880$, which corresponds to the operation region of the samples $\left(\mathrm{V}_{\mathrm{oc}}=1.1 \mathrm{~V}\right.$ at $\left.1 \mathrm{sun}\right)$. With fitting purposes, in addition to the elements included in the equivalent circuit inset in Figure 4A, extra series resistive and inductive elements were also considered.

$\underline{\text { Solar cell measurement }}$

Photovoltaic performance was measured using commercial solar simulators (Oriel, 450 $\mathrm{W}$, Xenon, AAA class). The light intensity was matched one sun (AM 1.5G or $100 \mathrm{~mW} \mathrm{~cm}^{-2}$ ) by calibrating with a Si reference cell equipped with an IR-cutoff filter (KG5, Newport), and it was done before each measurement. Current-voltage $(J-V)$ curves of the PSCs were obtained by applying an external voltage bias while measuring the current response using a Keithley 2400 digital source meter. The voltage scan rate was $25 \mathrm{mV} \mathrm{s}^{-1}$ as forward and reverse scan. Devices were not preconditioned such as light soaking or pre-voltage bias applied before starting the measurement. The cells were masked with an active area of $0.16 \mathrm{~cm}^{2} . E Q E$ was measured using IQE200B (Oriel) without bias light.

Stability tests were carried out in a sealed cell holder with a glass cover (house made), where argon gas were filled to remove the residual water and oxygen from the holder. In the glass cover, the $0.16 \mathrm{~cm}^{2}$ masks were equipped. The LED lamp used in the system was comprised a light intensitie of $100 \mathrm{~mW} \mathrm{~cm} \mathrm{~cm}^{-2} . \mathrm{J}-V$ curves were recorded by an electronic system using 22 bits delta-sigma analogic to digital converter. A scan rate of $25 \mathrm{mV} \mathrm{s}^{-1}$ with a step of 5 $\mathrm{mV}$ was used and the devices were kept on the temperature of $50^{\circ} \mathrm{C}$. Every 2 hours each measurement of $J-V$ measurement and maximum power point tracking were collected. A reference Si-photodiode was placed in the same holder to check the intensity of the light. 


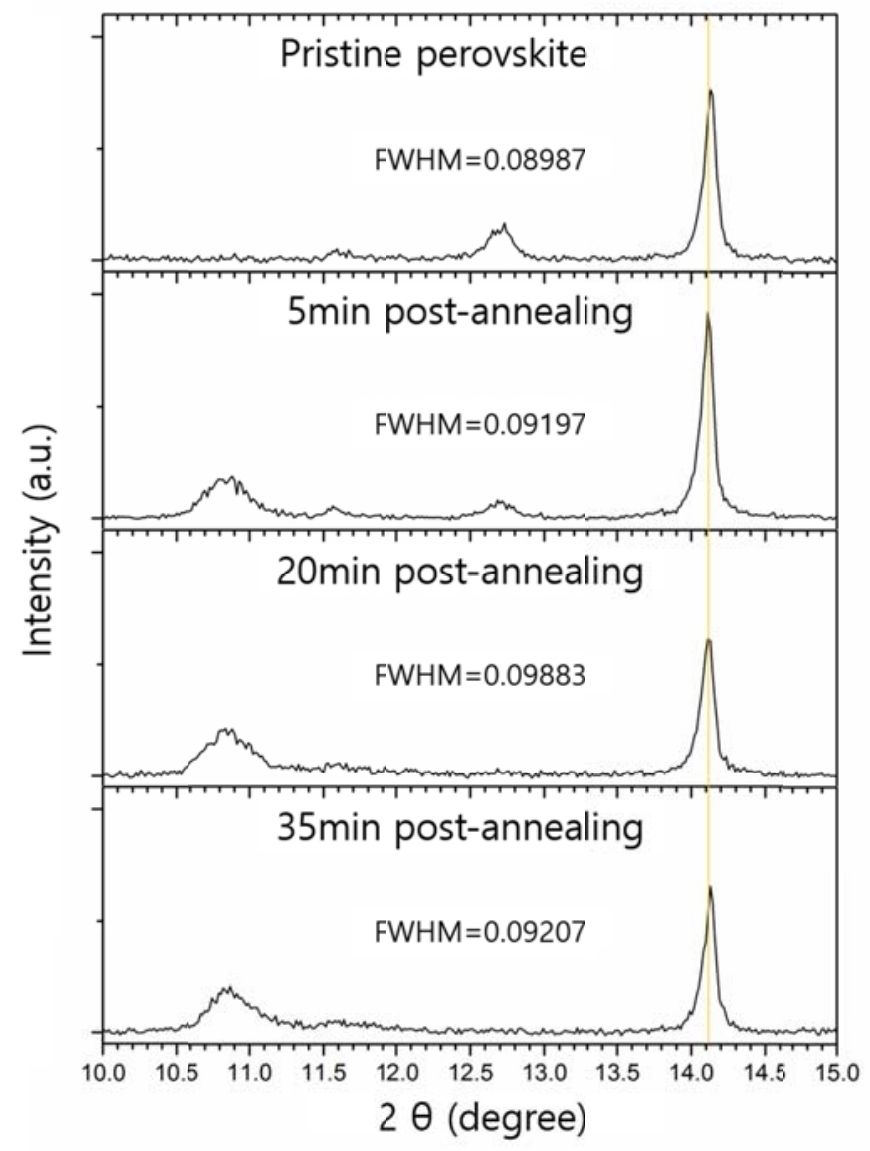

Fig. S1. Magnified XRD data of region around $14^{\circ}$, the main 3D CFMPIB perovskite peak, as annealing time after spin coating PEAI isopropanol solution $(10 \mathrm{mg} / \mathrm{ml})$. Full-width at halfmaximum of these CFMPIB perovskite peaks at $14.1^{\circ}$ were calculated and listed. 


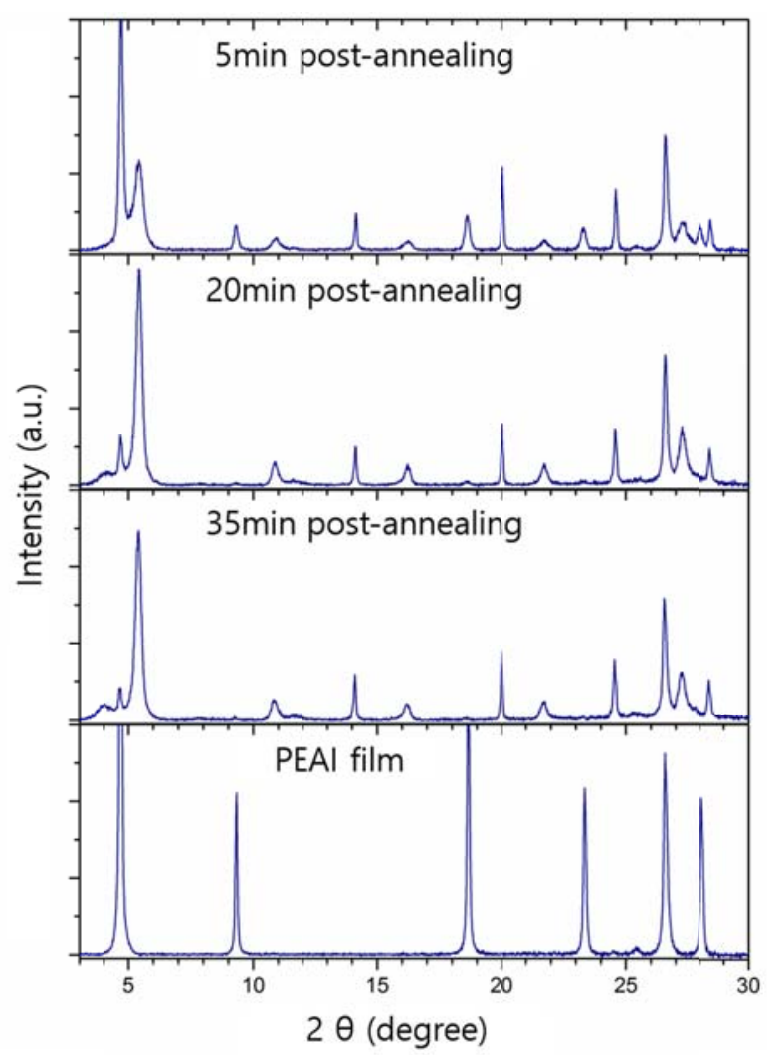

Fig. S2. XRD spectra for L-CFM/P perovskite films varying annealing time (5, 20, and $30 \mathrm{~min})$ and a PEAI film deposited on $\mathrm{a} \mathrm{TiO}_{2} / \mathrm{FTO}$ substrate by spin coating PEAI solution $(15 \mathrm{mg} / \mathrm{ml})$.

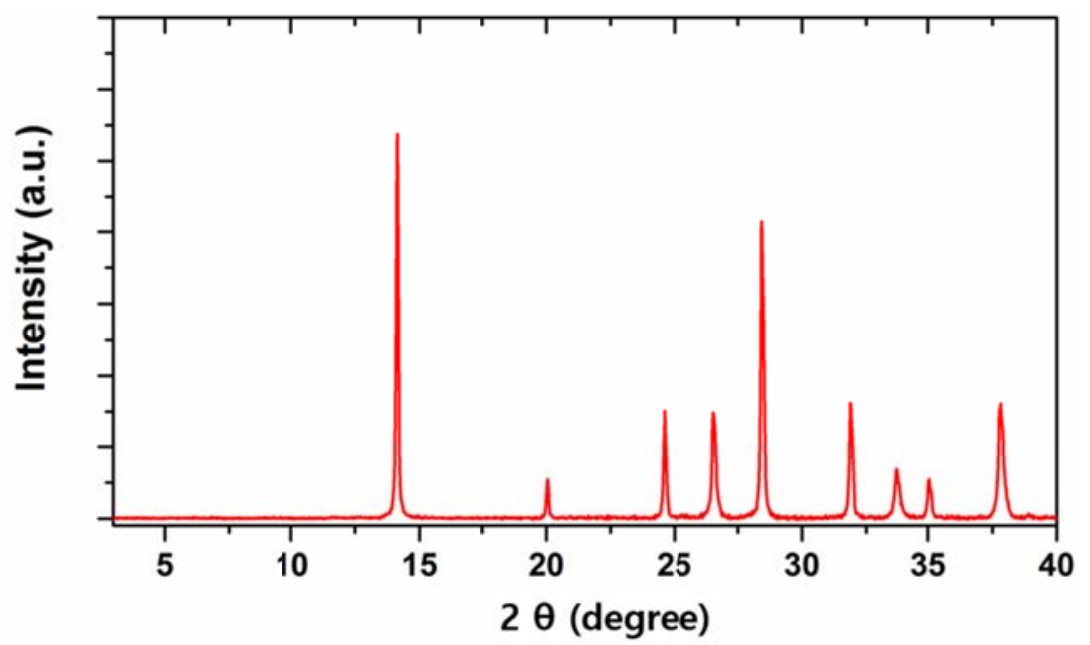

Fig. S3. XRD spectra of a CFMPIB+PEAI perovskite film. For the CFMPIB+PEAI film, another precursor solution was prepared by adding PEAI to the CFMPIB precursor solution, where the amount of PEAI was same to the excess molar ratio of $\mathrm{PbI}_{2}$ in the CFMPIB solution. The final composition of precursor solution was $\mathrm{PEA}_{0.05} \mathrm{Cs}_{0.1} \mathrm{FA}_{0.73} \mathrm{MA}_{0.13} \mathrm{PbI}_{2.53} \mathrm{Br}_{0.39}$. The perovskite film was fabricated by following same procedure for the CFMPIB perovskite film. 


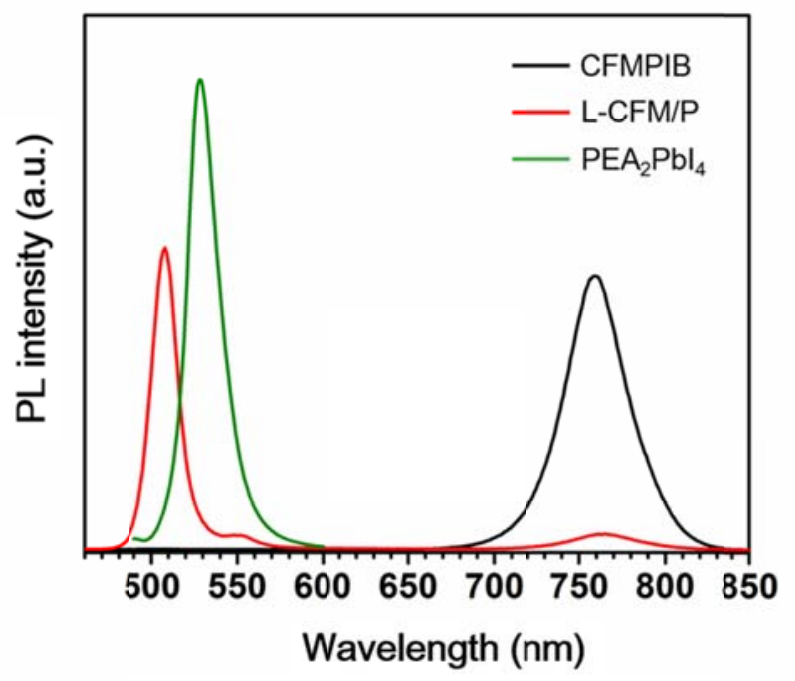

Fig. S4. Steady-state PL spectra of CFMPIB, L-CFM/P, and $\mathrm{PEA}_{2} \mathrm{PbI}_{4}$ perovskite films. The intensity was not normalized and the PL emission peaks were obtained from top surface of perovskite films.
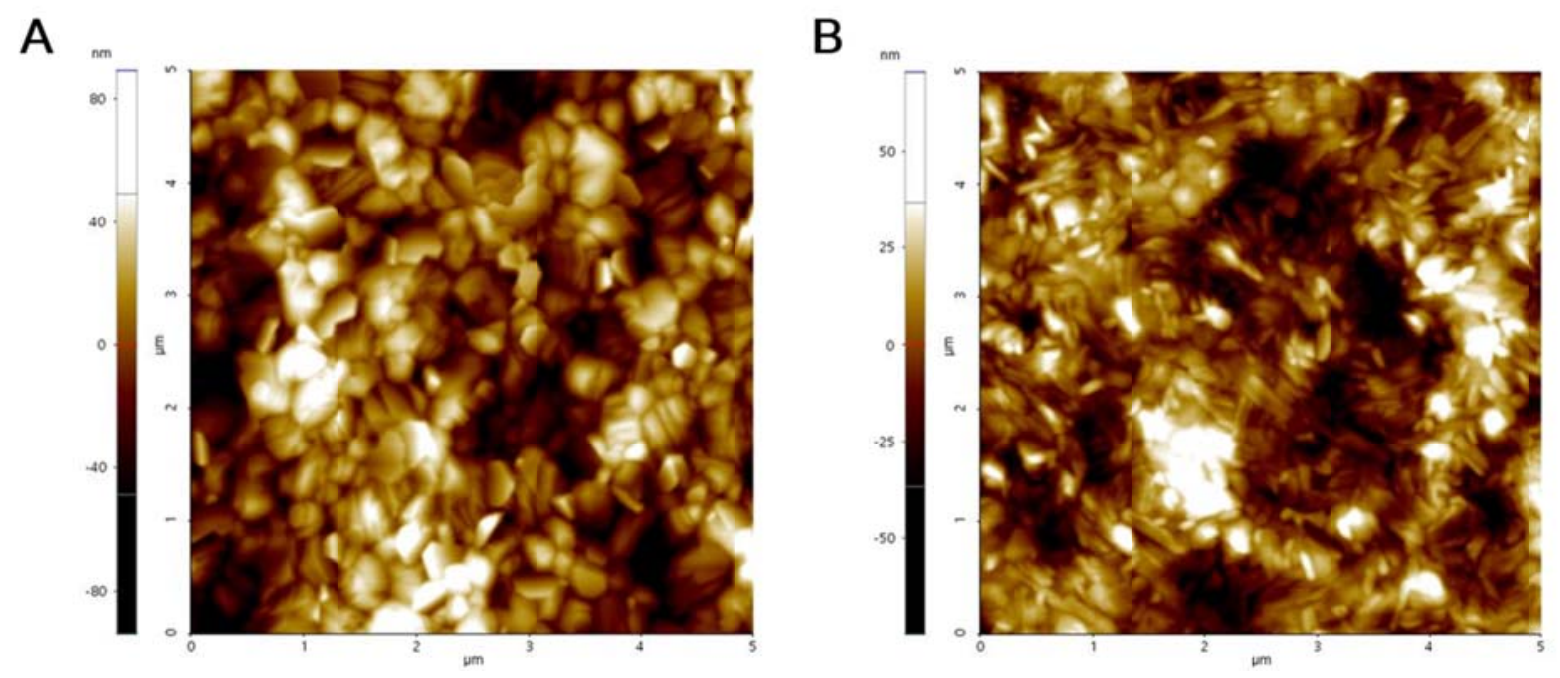

Fig. S5. Comparison on roughness of perovskite films from typical AFM measurement. The AFM images of CFMPIB (A) and L-CFM/P (B) are taken as 5x5 um². 
A

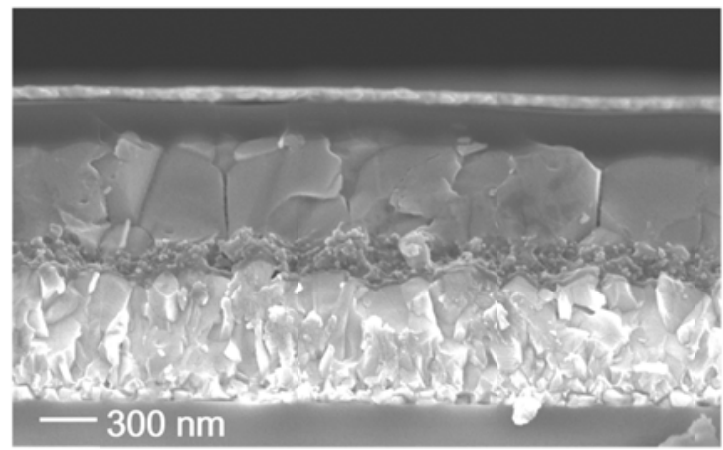

B

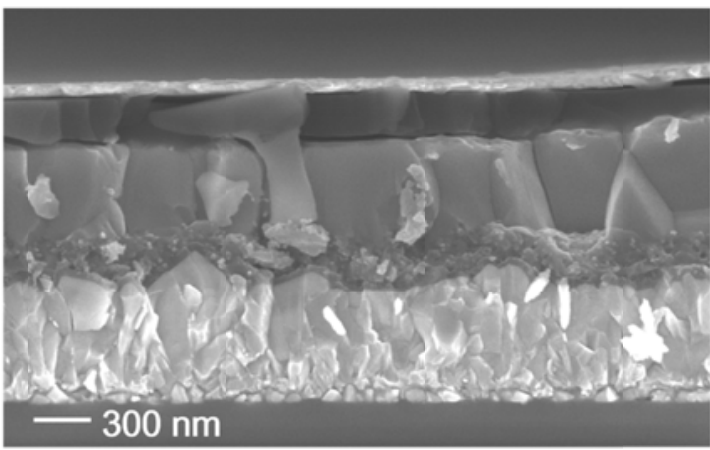

Fig. S6. Cross-sectional SEM images of the complete devices fabricated with CFMPIB (A) and $\mathrm{L}-\mathrm{CFM} / \mathrm{P}(\mathrm{B})$.

A

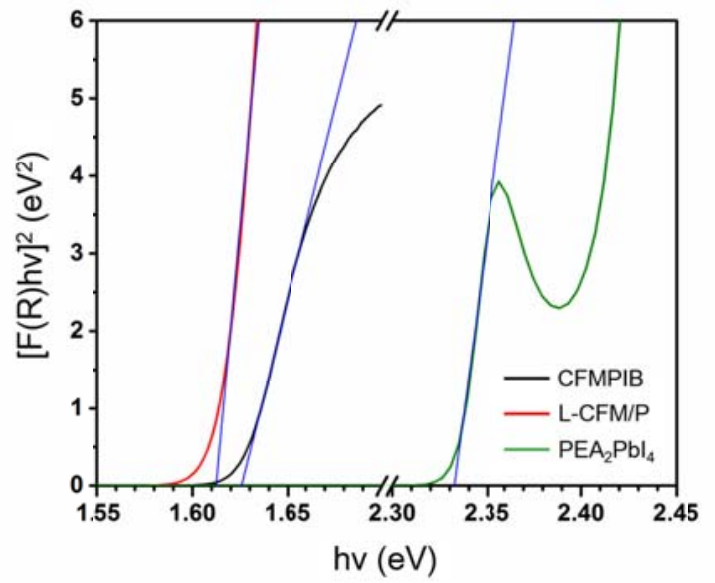

B

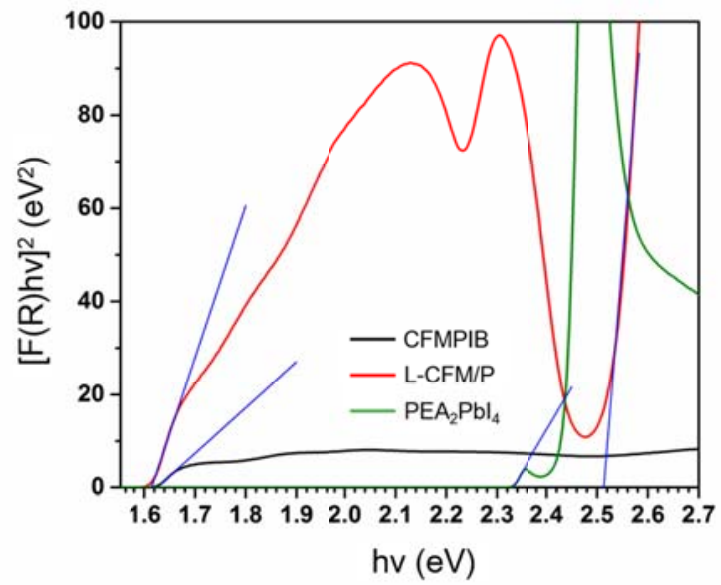

Fig. S7. Tauc plot derived from reflectance spectra of CFMPIB, L-CFM/P, and PEA $\mathrm{PbI}_{4}$ perovskite films assuming to direct band gap. (A) Magnified on intercept points and determination of optical band gaps. (B) Minimized to show the difference between CFMPIB and $\mathrm{L}-\mathrm{CFM} / \mathrm{P}$. 


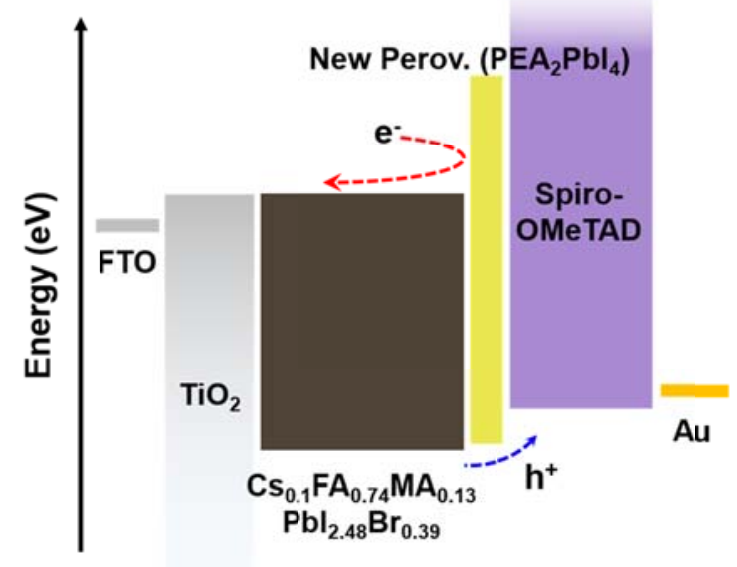

Fig. S8. Energy band diagram of L-CFM/P device and description of how the wrapping 2D perovskite layer improved the PCE. At a rear region of perovskite film, the new 2D perovskite having wide band gap can block transfer of excited electrons to the HTM layer. Valence band energy levels for CFMPIB and $\mathrm{PEA}_{2} \mathrm{PbI}_{4}$ are referred from previous papers using ultraviolet photoelectron spectroscopy (23). The band gap of perovskites are determined from PL measurement.

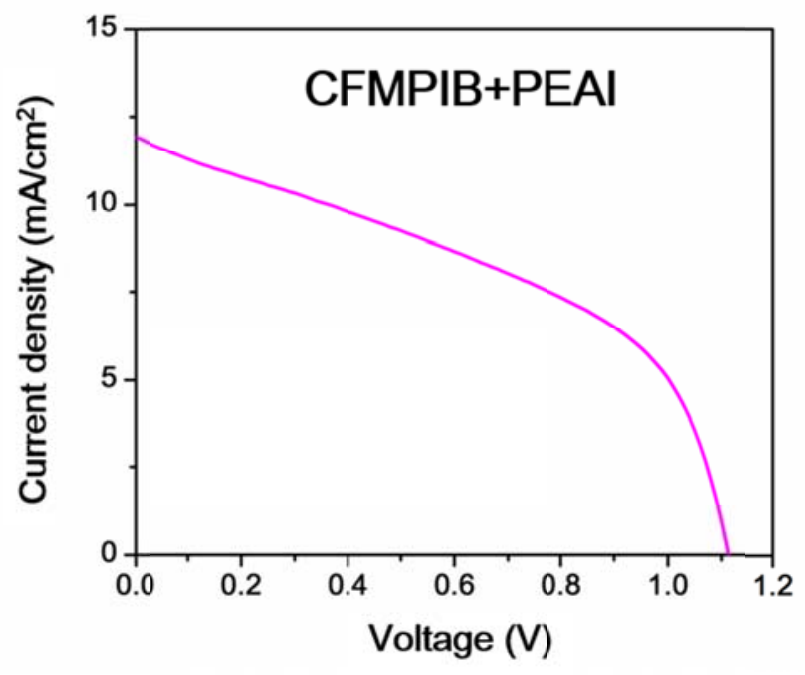

Fig. S9. J-V curve of a CFMPIB+PEAI device. 


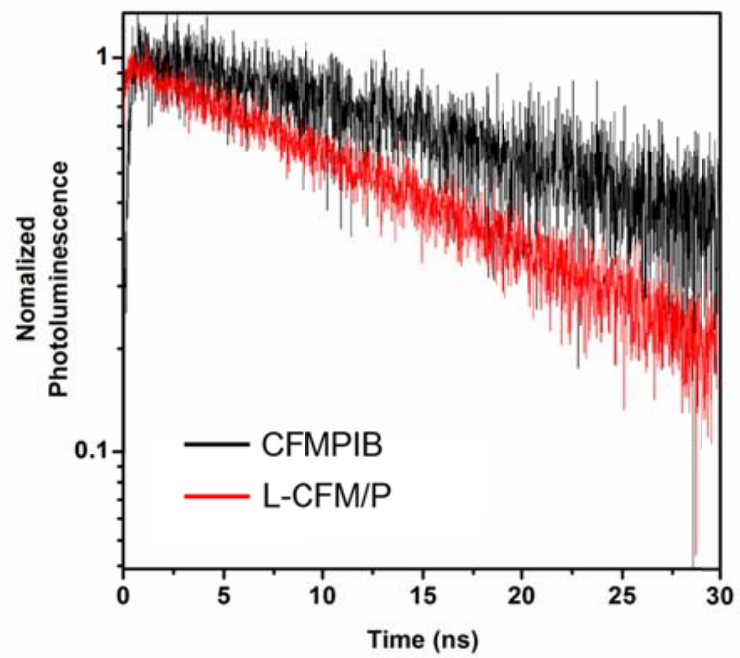

Fig. S10. Time-resolved PL decays of CFMPIB and L-CFM/P perovskite films. The measurement was carried out by monitoring the PL from the top side of perovskite films at 780 $\mathrm{nm}$ with $480 \mathrm{~nm}$ excitation.

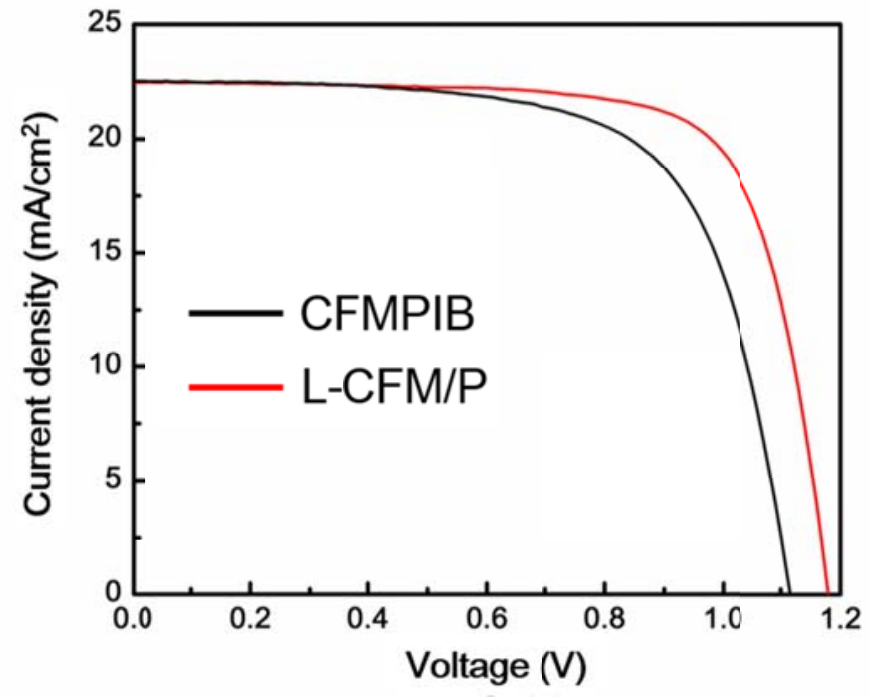

Fig. S11. J-V curves of devices based on $\mathrm{SnO}_{2}$ with CFMPIB and L-CFM/P perovskite. 


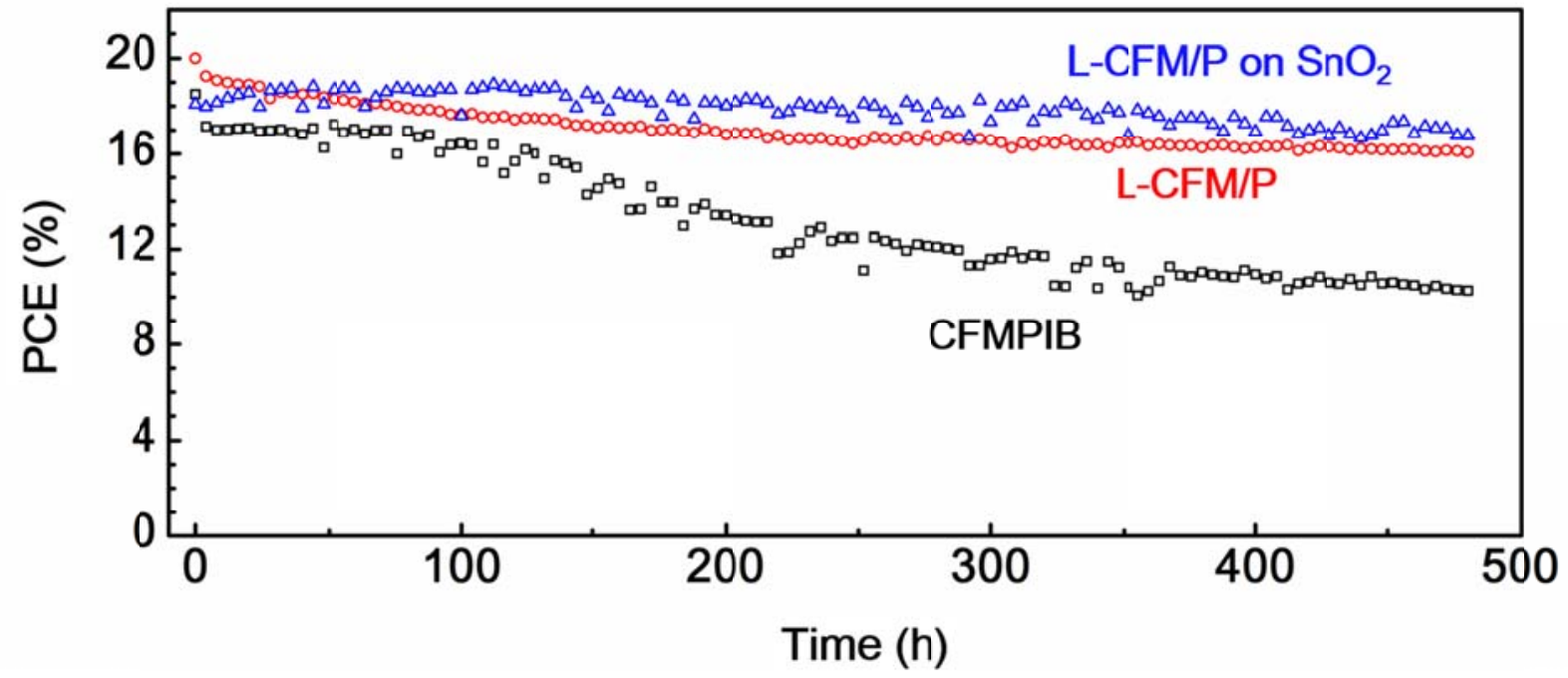

Fig. S12. Photostability examination of various PSCs. PCEs were obtained from reverse J-V scans of devices with CFMPIB and L-CFM/P based on meso- $\mathrm{TiO}_{2}$ and L-CFM/P based on planar $\mathrm{SnO}_{2}$. 